\title{
Non-communicable disease surveillance in India using Geographical Information System-An experience from Punjab
} \author{
Sheikh Mohd Saleem ${ }^{1}$, Chaitnya Aggarwal ${ }^{2}$, Om Prakash Bera ${ }^{3}$, Radhika Rana ${ }^{4}$, Gurmandeep Singh ${ }^{5}$, Sudip
} Bhattacharya $^{6}$

${ }^{1}$ Independent Public Health Researcher, Srinagar, Jammu, and Kashmir, India; ${ }^{2}$ Independent Researcher, North Carolina, United States; ${ }^{3}$ Principal Consultant, Global Health Advocacy Incubator, United States; ${ }^{4}$ Consultant, Health and Wellness Center, Department of Health and Family Welfare, Punjab; ${ }^{5}$ Lead Consultant, Health and Wellness Center, Department of Health and Family Welfare, Punjab; ${ }^{6}$ Independent Public Health Researcher, Dehradun, Uttarakhand, India.

\begin{tabular}{|c|c|c|c|c|c|c|c|}
\hline Abstract & Introduction & Methodology & Results & Conclusion & References & Citation & Tables/ Figures \\
\hline
\end{tabular}

\section{Corresponding Author}

Dr Sheikh Mohd Saleem, Independent Public Health Researcher, Srinagar, Jammu and Kashmir, India

E Mail ID: saleem.900@gmail.com

\section{Citation}

Saleem SM, Aggarwal C, Bera OP, Rana R, Singh G, Bhattacharya S. Non-communicable disease surveillance in India using Geographical Information System-An experience from Punjab. Indian J Comm Health. 2021;33(3):506-511. https://doi.org/10.47203/IJCH.2021.v33i03.017

\section{Article Cycle}

Source of Funding: Nil Conflict of Interest: None declared

\begin{tabular}{|c|}
\hline Received: 23/07/2021; Revision: 21/08/2021; Accepted: 05/09/2021; Published: 30/09/2021 \\
\hline This work is licensed under a Creative Commons Attribution 4.0 International License. \\
\hline
\end{tabular}

\section{Abstract}

"Geographic information system (GIS) collects various kinds of data based on the geographic relationship across space." Data in GIS is stored to visualize, analyze, and interpret geographic data to learn about an area, an ongoing project, site planning, business, health economics and health-related surveys and information. GIS has evolved from ancient disease maps to 3D digital maps and continues to grow even today. The visual-spatial mapping of the data has given us an insight into different diseases ranging from diarrhea, pneumonia to non-communicable diseases like diabetes mellitus, hypertension, cardiovascular diseases, or risk factors like obesity, being overweight, etc. All in a while, this information has highlighted health-related issues and knowledge about these in a contemporary manner worldwide. Researchers, scientists, and administrators use GIS for research project planning, execution, and disease management. Cases of diseases in a specific area or region, the number of hospitals, roads, waterways, and health catchment areas are examples of spatially referenced data that can be captured and easily presented using GIS. Currently, we are facing an epidemic of non-communicable diseases, and a powerful tool like GIS can be used efficiently in such a situation. GIS can provide a powerful and robust framework for effectively monitoring and identifying the leading cause behind such diseases. GIS, which provides a spatial viewpoint regarding the disease spectrum, pattern, and distribution, is of particular importance in this area and helps better understand disease transmission dynamics and spatial determinants. The use of GIS in public health will be a practical approach for surveillance, monitoring, planning, optimization, and service delivery of health resources to the people at large. The GIS platform can link environmental and spatial information with the disease itself, which makes it an asset in disease control progression all over the globe.

\section{Keywords}

Geographical Information System; Disease surveillance; Non-Communicable Disease

\section{Introduction}

Population data is an essential source of information for any public health professional, medical statistician, or researcher etc. When presented as virtual images based on geographic relationships, quantity or type of disease, population data can be very thrilling. On similar lines, a computer-based science and technology tool, "Geographic information system (GIS) collects various kinds of data based on the geographic relationship across space."

There are five main principles by which the GIS structure usually run. These are: (a) A spatially reference data for collection and stockpile into a relational geodatabase, (b) For physically storage and collection of the data hardware is required, (c) Software is necessary by which the user assembles the interface algorithms, and can access the database, ask questions and can perform the analysis of 
the captured data (d) The algorithms (mathematical/statistical) and measures for data management, and (e

) The public, who are both creators and consumers of spatial data. (1) In short, GIS is a database those diverse users can use to meet various information needs. A series of information captured by GIS is known as "layers". Individually these layers contain raw data (e.g., topographic data/satellite data/ thematic data like health services. The most exciting feature of GIS is that it can change spatial data into the geographic data or coordinate system, which enriches the users' information. (1)

Basically, the software applications that are used in public health can be classified into three distinct programs: ArcView (ArcView software is a desktop version of GIS from the Environmental Systems Research Institute, Inc), Health Mapper (To address medical and health-based problems, designed and developed by the WHO and UNICEF for mapping health services) and EpiMap (This software was produced by the Center for Disease Control, USA.) uses shapefile format which is the commonly available format of data availability.

As previously discussed, GIS stores the data to visualize data, analyze and interpret geographic data to learn about an area, an ongoing project, site planning, business, health economics and health-related surveys and information, and many things, among others. (2) Details are given in (Table-1)

Most are unaware that the field of medical geography is as old as the medical sciences. The history of this field tells us the tale, which is supported by contemporary examples of GIS, public health influences, spatial mapping and the future trend of this discipline which is backed by massive data. GIS has evolved from ancient disease maps to 3D digital maps and continues to grow even today. The visualspatial mapping of the data has given us an insight into different diseases ranging from diarrhea, pneumonia to diseases like diabetes mellitus, cardiovascular diseases, hypertension, or risk factors like obesity, being overweight, etc. All in a while, this information has highlighted health-related issues and knowledge about these in a contemporary manner worldwide. (3)

In GIS, a wide variety of geo-referenced data can be analyzed among various topics associated with a location on a map or anything that can be mapped. (4) In GIS, the data is in the form of attributes or description. We have a data set of district hospitals in a particular state that can be mapped. Using the descriptive analysis and associated attributes, we can determine and display the number of bed available for the patients, specialized services offered to the community, the number of doctors available, etc. And using the analytical data, the disease pattern within the community, rates of a particular disease, and disease distribution around the health facility can be determined. Researchers, scientists, and administrators use GIS for research project planning, execution, and disease management. (2) Cases of diseases in a specific area or region, the number of hospitals, roads, waterways, and health catchment areas are examples of spatially referenced data that can be captured and easily presented using GIS. (4) Currently, we are facing an epidemic of noncommunicable diseases, and a powerful tool like GIS can be used efficiently in such a situation. GIS can provide a powerful and robust framework for effectively monitoring and identifying the leading cause behind such diseases. (3) As GIS has over and above provided an improved response to the public health problems, its popularity and adoption have been increased among health-related domains and nationwide settings over the past decade. (5)

Public health issues are often complex and solving them requires complex interdisciplinary measures. GIS, which provides a spatial viewpoint regarding the disease spectrum, pattern, and distribution, is of particular importance in this area and helps better understand the dynamics and spatial determinants of disease transmission. (5) About $17.7 \%$ of the world's population resides in India in 2021. (6) The enormous size of the population has commensurate public health challenges to deal with. India bears the world's most considerable burden of chronic conditions such as diabetes, hypertension, obesity and cancers. (7) These chronic conditions are related to the risk factors which have environmental influence and have spatial parameters too. Geographic mapping methods like GIS can help understand the ecological and spatial determinants of such disease conditions. This manuscript focuses on detailing the evolutionary history of the GIS, its uses in different sectors, including the health sector, the current status use of GIS in the public health system, and the way forward.

Brief history of Medical Geography: Medical geography uses geographic techniques such as mapping and GIS to study the impact of environmental conditions on one health. Using medical geography can be found in several ancient literature pieces from China, Greece, and India. Hippocrates has first observed human health's relationship with the surrounding environment in the 5 th Century BCE. $(1,8)$ Some earlier studies have used medical geography to estimate malaria prevalence among those living in higher versus lower plains and found the malarial prevalence more significant among those living near water bodies located at lower tables. (8) During the 18th century, French physicians coined the term medical geography, and it was Leonhard Ludwig Finke, a German physician who created the first disease map in 1792. The map became a vital assessment tool for effective learning, understanding disease incidence, disease spread, and determining spatial associations with the environment. (8) There are many such examples of medical geography, including the mapping of cholera cases by Dr Robert Baker in Leeds, dot density map of cholera outbreak in Exeter by Dr Thomas Shapter, and series of cholera maps of the 
INDIAN JOURNAL OF COMMUNITY HEALTH / VOL 33 / ISSUE NO 03 / JUL-SEP 2021 British Isles by Augustus Petermann. (9) But perhaps the most famous and known to almost everyone is the favorite dot map created by John Snow, the father of modern epidemiology. John Snow identified the cholera outbreak's reason and demonstrated the water-borne origin of the disease by plotting cholera related mortality in London on a hand-drawn map. Additionally, he plotted the location of the water pumps. He identified the area with the highest clustering of cases, the Broad Street Pump, by drawing concentric circles around the served area of pumps. (8) He then removed the handle of the pump, and consequently, there was an end to the recent cholera disease cases. John snow's research on cholera outbreak eventually became a part of disease diffusion mapping which states that disease starts at a central point and spreads as per the conditions and patterns of the surrounding environment. (2) These early mapping geographic techniques proved much helpful in explaining a disease's relationship with the surrounding environmental conditions. During the last century, with modern techniques, maps and devices, medical geography has undergone a significant transition with many new publications, literature, and societies fervent to it. (10)

Milestones of GIS evolution (11): Over the past six decades, we have seen GIS evolving from a simple hand drawn concept to a complete scientific package. Several milestones mark the evolution of GIS from a elementary tool to a completely advanced, modern day scientific technocrat platform which is enlisted in (Table 2).

Use of GIS in other sectors: GIS has been instrumental in many sectors, and its application and technical approach to analysis has significantly enhanced its use and domain. GIS has proved over and again as a powerful decisionmaking tool for any industry because of its variability in analyzing different sets of data viz a viz demographic, topographic and environmental. Below mentioned are some of the sectors where GIS helps industries make informed decisions. (12)

a) Mapping: As GIS provides a visual interpretation of data, its use for navigation purposes has been instrumental. Applications like Google maps is the best example of the use of GIS for mapping purpose.

b) Tele information and Network Providers: The use of spatial and geo-referenced data is used by organizations to develop designs, planning, maintenance and optimization activities. This data helps in the identification of locations where the customers are located.

c) Analysis of accidents and Hot Spot analysis: Data from Gls can be analyzed to identify the location of accidents happening on roads, plan better traffic plans, and identify accident Hot Spot for better optimization of service delivery.

d) Urban Planning: The growth of urban localities can be visualized and expansions identified. GIS data can
[GIS NCD Surveillance] | Saleem SM et al help us better plan the development of urban localities keeping in view the surrounding environment.

e) Traffic management: Data from GIS can be effectively used in the planning of new roads, and rail routes etc., due to the incorporation of topographic and environmental data in the GIS platform.

f) Environmental analysis: GIS data has been able to integrate human civilization's impact on the environment, so data interpretation from GIS can help plan conservative measures to protect natural resources.

g) Mitigation and management of disasters: Efficient GIS platform can help assess environmental risk factors deemed to cause disasters and plan more efficiently in risk analysis and mitigation activities. Areas affected by floods, cyclones, earthquakes etc., can be identified, and better planning for relief efforts can be done.

h) Banking system: Banks' services are usually customer-driven, and GIS plays an essential role in organizing, planning, and decision-making activities for the bank industry.

i) Taxation: GIS platform provides an excellent opportunity for the taxation industry to build permits, engineering assignments and offers a system to identify locations for property tax extraction.

j) Geological science: Analysis of soil, rocks and water, seismic assessments and creation of 3D virtual maps are some of the usefulness of GIS for geologists.

There is a profound impact of GIS on the business and industries as well as on the public. Sooner or later, we shall realize the importance of GIS data in our lives and work if only the technologies were eliminated someday.

Current use of GIS in public health sector: Over the past decade, we have seen an enormous literature review pertaining to the research methods and analytical techniques using geography, spatial mapping and epidemiology. May epidemiological studies have employed GIS in their workplan, especially in health disparities and related behaviour and availability of resources. Furthermore, the GIS platform application has been more fundamentally used in cancer research and field epidemiology with special mention to environmental factors. (13) GIS platform provides access to determine the proximity of cases, aggregation, and clustering of patients to find out the hot spots of any disease. (12) Currently, the determination of disease cluster or Hot Spot is the main application of GIS in epidemiology. However, GIS in disease surveillance and monitoring has also been explored and has proved much useful. (14)

Use of GIS in understanding dynamics of NonCommunicable Diseases (NCDs): The global contribution of NCD deaths is estimated at around $68 \%$ of all deaths because of all causes, and these figures are somewhat the same for India, where $60 \%$ or 5.87 million deaths occur 
each year because of NCDs. The rising NCDs, especially in LMIC like India, are attributed to an epidemiological health transition among the people due to rapid urbanization, sedentary lifestyle, endocrine disruptions, and transforming nutritional preferences. Diets rich in fat, salt and sugars, and the lack of physical activity are regarded as the major contributing factor for NCDs. The global population has been exposed to unhealthy diets over the last few decades, increasing the incidence and overall prevalence of being overweight. It is critical to address this issue of rising NCDs in all forms before it's too late.

The use of GIS and the global positioning system (GPS) can be an effective intervention to ascertain the habitation of those with the NCDs. Using the GIS platform's spatial technology, the exact location of an individual suffering from NCDs can be determined. Simultaneously, the geographic coordinates would give an idea about the environmental risk factors and risk factors affecting the healthy behaviour of that individual. Among NCDs' risk factors are the behavioural characteristics, which are critical to effective prevention and treatment. Most behavioural factors that cause NCDs include intake of an unhealthy diet, diet rich in fat, salt and sugars, physical inactivity, alcohol consumption, and cigarette smoking.

Using geospatial technology and spatiotemporal epidemiological tools, we can understand the disease dynamics behind the NCD distribution within a particular community or geographical area. (4) Furthermore, individuals with the unhealthiest behaviour can be located easily. Clustering such harmful behaviour at a specific geographic area could hint towards any particular risk factor present within the surrounding community. GIS platform can further help in associating a typical unhealthy behaviour with likely geographically associated risk factor. Using GIS mapping, the NCD cases can be easily mapped along with a particular geographic space. Health officials can quickly identify them to optimize interventions, planning's, surveillance and monitoring activities. (11) Such planning interventions could prove highly beneficial and cost-effective to the Governments in the prevention and control of NCDs.

Case Study: Here, we present a case study from the state of Punjab, India. The study is based on the teleconsultation data calls received during the COVID-19 lockdown from various Punjab districts. A total of 37265 calls were received during March 2020 up to March 2021 for teleconsultations regarding various health issues. All the calls were recorded with the patients' consent, and socio-demographic and clinical diagnosis data were collected. For this manuscript, only data related to NCDs (diabetes and hypertension) were analyzed using appropriate statistical software and presented in the form of frequency and percentage. A total of 37265 teleconsultations were done, which were associated with NCDs, especially diabetes type-2 and hypertension
(Table-3). Most calls received from patients suffering from hypertension 5254(62.2\%), followed by those with diabetes mellitus 3201(37.8\%). Among the districts, most calls related to NCDs were received from the districts of Mansa (1692), Rupnagar (1210), Moga (1060), and Ludhiana (634). District wise NCD case consultation done during the study period are shown in (Table 3).

Inference from the Data: As is quite evident that there is a high prevalence of NCDs within the study population. Among the total NCDs, 5254(62.2\%) had hypertension and $3201(37.8 \%)$ had diabetes mellitus. (Figure-1) In order to plan intervention for such individuals who are suffering from chronic diseases, including NCDs, GIS platforms can be much helpful. GIS helps determine patients' location, clustering of cases, environmental factors responsible for such disease dynamics and overall, helps in making efficient decisions and plan treatment modalities with fewer costs involved.

It also helps in finding unhealthy behaviour among the cases, relation and distance of various health institutions and other sectors to implement preventive measures involving a multi-sectoral approach. Figure 1 shows the district map of the State of Punjab with teleconsultations' frequency based on NCDs from each district. GIS platform, helps in locating the geographic area with many cases or clustering of cases and helps in appropriate planning and preventive health measures.

\section{Conclusion}

There are demand and a lot of scope for GIS in the field of health sciences. GIS is an evolving field and parallels the advancement in the control of diseases. The use of GIS will be a practical approach for surveillance, monitoring, planning, optimization, and service delivery of health resources to the people at large. The GIS platform can link environmental and spatial information with the disease itself, which makes it an asset in the progression of disease control all over the globe.

Ethical Issues: The study has used secondary data for the case study for which no ethical clearance was required. Although, permission to use the data was obtained from the competent authority.

\section{References}

1. Aghajani J, Farnia P, Velayati AA. Impact of geographical information system on public health sciences. Biomed Biotechnol Res J 2017; 1:94100.

2. Briney A. Overview of Public Health and GIS GIS Lounge [Internet]. GIS Lounge. 2014 [cited 2021 Mar 26]. Available from: https://www.gislounge.com/overview-public-health-gis/

3. Musa GJ, Chiang PH, Sylk T, et al. Use of GIS Mapping as a Public Health Tool-From Cholera to Cancer. Health Serv Insights. 2013;6:111-16. doi:10.4137/HSI.S10471

4. Centers for Disease Control and Prevention. GIS and Public Health at CDC. 2016 [cited 2021 Mar 26];55:17-20. Available from: https://www.cdc.gov/gis/index.htm

5. Ruiz M, Sharma A. Application of GIS in public health in India: A literature-based review, analysis, and recommendations. Indian J Public Health [Internet]. 2016;60(1):51-8. Available from: https://www.ijph.in/article.asp?issn=0019-557X0 . 
6. India Population (2021) - Worldometer [Internet]. [cited 2021 Mar 26]. Available from: https://www.worldometers.info/worldpopulation/india-population/

7. Bhojani U, Beerenahalli TS, Devadasan R, Munegowda CM, Devadasan $\mathrm{N}$, Criel B, et al. No longer diseases of the wealthy: Prevalence and health-seeking for self-reported chronic conditions among urban poor in southern India. BMC Health Serv Res 2013;13:306.

8. Barrett FA. Finke's 1792 map of human diseases: The first world disease map? Social Science \& Medicine. 2000;50(7):915-21.

9. Gilbert EW. Pioneer maps of health and disease in England. Geographical Journal. 1958;124(2):172-83.

10. Light RU. The progress of medical geography. Geographical Review. 1944;34(4):636-41
11. Esri. History of GIS | Early History and the Future of GIS - Esri [Internet] 2018:1-2. Available from: https://www.esri.com/en-us/what-isgis/history-of-gis

12. Tate L. 20 Ways GIS Data is Used in Business and Everyday Life. Model Earth Syst Environ. 2018:1-10. Available from: https://nobelsystemsblog.com/gis-data-business/

13. Auchincloss AH, Gebreab SY, Mair C, Diez Roux AV. A review of spatial methods in epidemiology, 2000-2010. Annual Review of Public Health. 2012;33:107-22.

14. Clarke KC, McLafferty SL, Tempalski BJ. On epidemiology and geographic information systems: a review and discussion of future directions. Emerg Infect Dis. 1996;2(2):85-92.

\section{Tables}

\section{TABLE 1 GIS DATA FEATURES USED IN PUBLIC HEALTH PROGRAMS BY WORLD HEALTH ORGANIZATION}

\begin{tabular}{|c|c|}
\hline Data boundary & Data feature \\
\hline Map files digital boundary maps & $\begin{array}{l}\text { Global border map } \\
\text { Regional border maps } \\
\text { Subnational } \\
\text { Administrative Purposes }\end{array}$ \\
\hline Geographic features & $\begin{array}{l}\text { Road network maps } \\
\text { Rivers, lakes } \\
\text { Parks } \\
\text { Land use/Forests } \\
\text { Elevations }\end{array}$ \\
\hline Geographic features & $\begin{array}{l}\text { Location of cities, Towns, } \\
\text { Location of settlements by type } \\
\text { Urban areas, Rural areas }\end{array}$ \\
\hline Health services data & $\begin{array}{l}\text { Location of health services by type } \\
\text { Health district boundaries } \\
\text { Health-care catchment areas } \\
\text { Location of laboratories } \\
\text { NGO intervention areas }\end{array}$ \\
\hline Social services & $\begin{array}{l}\text { Location of schools by type } \\
\text { Location of water supply points by type } \\
\text { Location of trading areas/markets }\end{array}$ \\
\hline Data files demographic data & $\begin{array}{l}\text { National population estimates } \\
\text { District population estimates } \\
\text { Village/town/city population estimates } \\
\text { Population density distribution model }\end{array}$ \\
\hline
\end{tabular}

\section{TABLE 2 HISTORICAL MILESTONES}

\begin{tabular}{|c|c|}
\hline $\begin{array}{l}\text { The Early History of } \\
\text { GIS (1960) }\end{array}$ & $\begin{array}{l}\text { With the emerging of computer technology, the concept of descriptive computational geography also emerged. } \\
\text { In } 1960 \text { s, academic community started research work using GIS. } \\
\text { Later, the "National Center for Geographic Information and Analysis" started working on key topics related to GIS, including } \\
\text { visualization and spatial analysis. }\end{array}$ \\
\hline The First GIS (1963) & $\begin{array}{l}\text { In 1963, the revolutionary work by Roger Tomlinson's to initiate, plan, and develop the Canada Geographic Information System } \\
\text { resulted in the first computerized GIS. } \\
\text { Roger Tomlinson also gave GIS its name. }\end{array}$ \\
\hline $\begin{array}{l}\text { The Harvard } \\
\text { Laboratory (1965) }\end{array}$ & $\begin{array}{l}\text { In 1964, SYMAP the first computer mapping software was developed by Howard Fisher. } \\
\text { Later in 1965, a Harvard Laboratory for Computer Graphics was established, which became the center for visualization and spatial } \\
\text { analysis. }\end{array}$ \\
\hline $\begin{array}{l}\text { Esri is Founded } \\
\text { (1969) }\end{array}$ & $\begin{array}{l}\text { In 1969, members from the Harvard lab-Jack Dangermond and Laura founded Environmental Systems Research Institute, Inc. } \\
\text { (Esri). } \\
\text { Later, GIS was pragmatic to support land planning by Esri to make informed decisions and problem-solving methods. }\end{array}$ \\
\hline $\begin{array}{l}\text { GIS Goes } \\
\text { Commercial (1981) }\end{array}$ & $\begin{array}{l}\text { With the development of super computers, Eris also improved its GIS software with robust technology and started working in } \\
\text { projects dealing with real-world problems which gained a lot of attention and recognition for the company. } \\
\text { As the need for examining an increasing quantity of projects become a necessity, Esri developed and launched ARC/INFO-the } \\
\text { first commercially available GIS product. The technology was launched in } 1981 \text { and began the evolution and journey of Esri into } \\
\text { a software company. }\end{array}$ \\
\hline GIS Current Status & $\begin{array}{l}\text { GIS enable user's ability to create their own digital map layers to help solve real-world problems just with a click of few buttons. } \\
\text { GIS has also evolved into a means for sharing data and collaboration on a larger scale, inspiring a bigger vision that is now rapidly } \\
\text { becoming a big reality-a continuous, overlapping, and interoperable GIS database of the world, about virtually all developing } \\
\text { subjects. } \\
\text { Today, hundreds of thousands of leading organizations are sharing their work and creating billions of maps every day to tell their } \\
\text { stories and reveal patterns, trends, and relationships about everything to the world through GIS system. }\end{array}$ \\
\hline
\end{tabular}


TABLE 3 DISTRIBUTION OF NON-COMMUNICABLE DISEASES (DM AND HTN) AMONG VARIOUS DISTRICT OF STATE OF PUNJAB. (BASED ON TELE-CONSULTATIONS DONE BETWEEN MARCH 2020 TO MARCH 2021)

\begin{tabular}{|c|c|c|c|c|}
\hline \multirow[t]{2}{*}{ S. No } & \multicolumn{4}{|c|}{ Diagnosis } \\
\hline & District & Diabetes Mellitus & Hypertension & Total \\
\hline 1 & Amritsar & 137 & 214 & 351 \\
\hline 2 & Barnala & 102 & 118 & 220 \\
\hline 3 & Bathinda & 67 & 217 & 284 \\
\hline 4 & Faridkot & 39 & 112 & 151 \\
\hline 5 & Fatehgarh Sahib & 56 & 117 & 173 \\
\hline 6 & Fazilka & 79 & 132 & 211 \\
\hline 7 & Ferozepur & 64 & 92 & 156 \\
\hline 8 & Gurdaspur & 78 & 145 & 223 \\
\hline 9 & Hoshiarpur & 112 & 281 & 393 \\
\hline 10 & Jalandhar & 76 & 147 & 223 \\
\hline 11 & Kapurthala & 20 & 31 & 51 \\
\hline 12 & Ludhiana & 248 & 386 & 634 \\
\hline 13 & Malerkotla & 2 & 0 & 2 \\
\hline 14 & Mansa & 582 & 1110 & 1692 \\
\hline 15 & Moga & 485 & 575 & 1060 \\
\hline 16 & Mohali & 178 & 212 & 390 \\
\hline 17 & Muktsar Sahib & 134 & 156 & 290 \\
\hline 18 & Pathankot & 36 & 54 & 90 \\
\hline 19 & Patiala & 87 & 143 & 230 \\
\hline 20 & Rupnagar & 489 & 721 & 1210 \\
\hline 21 & Sangrur & 84 & 213 & 297 \\
\hline \multirow[t]{2}{*}{22} & Tarn Taran & 46 & 78 & 124 \\
\hline & & $3201(37.8 \%)$ & $5254(62.2 \%)$ & $8455(100 \%)$ \\
\hline
\end{tabular}

\section{Figures}

FIGURE 1 DISTRIBUTION OF NCD (DM AND HTN) AMONG VARIOUS DISTRICT OF STATE OF PUNJAB.
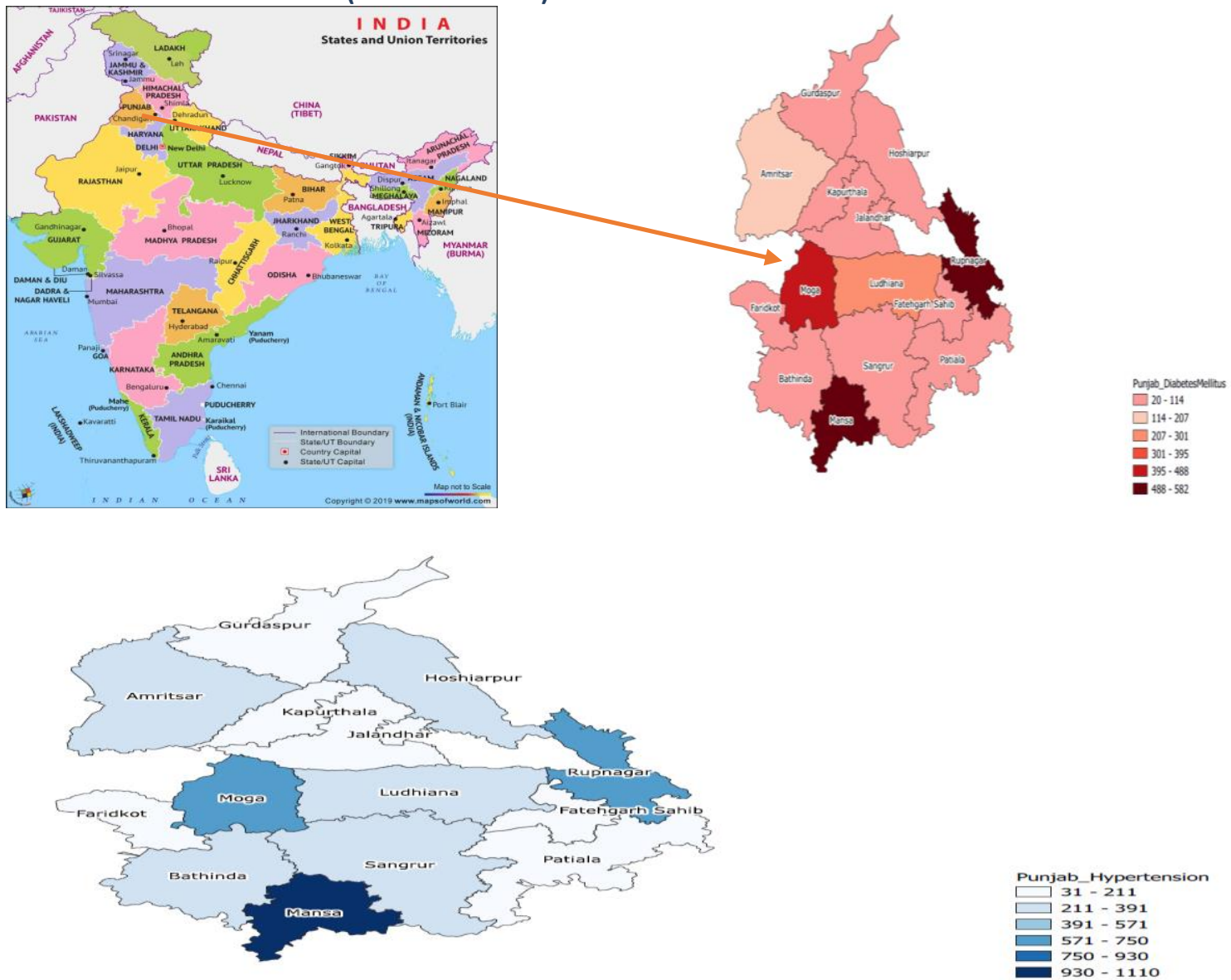